\title{
Quality of Life in Bladder Cancer Patients Treated with Radical Cystectomy and Orthotopic Bladder Reconstruction versus Bladder Preservation Protocol
}

\section{Mohamed I El-Sayed ${ }^{1 *}$, Ahmed S El-Azab² and Mohamed A El-Gammal'}

${ }^{1}$ Department of Radiation oncology, South Egypt Cancer Institute, Assiut University, Egypt

${ }^{2}$ Department of Urology, Faculty of Medicine, Assiut University, Egypt

\section{Abstract}

Background: Tri-modality bladder sparing therapy in selected bladder cancer patients may be an alternatives treatment option to immediate radical cystectomy as it may result in satisfactory Quality Of Life (QOL). The present study evaluated the effects of this conservative approach versus surgical approach, i.e. Radical Cystectomy (RC) and orthotopic neobladder, on QOL of patients.

Patients and methods: This is a prospective study of patients with bladder cancer in group I (using tri-modality bladder sparing therapy) and group II (using RC and orthotopic neobladder). Patients in both groups were subjected to interview NCCN-FACT FBISI18 questionnaire, inquiring about physical and emotional disease related symptoms, treatment side effects and function and well being. SPSS version18 software was used for statistical analysis.

Results: Internal consistency of the 18 items in both groups was assessed by Cronbach's a which was adequate at 0.89 at Group I and 0.84 at Group II. Univariate analysis showed that there were statistically significant difference $(p<0.05)$ in favor of group I patients compared to those in group II, regarding bladder function, potency and bowel symptoms. Multivariate analysis revealed that only $\mathrm{T}$ stage significantly affected physical and emotional disease related symptoms, and treatment side effects subscales in favor of bladder preservation group.

Conclusions: Tri-modality bladder sparing therapy resulted in well-functioning bladders, mild bowel symptoms, and satisfactory sexual functioning in contrast to the surgical approach in bladder cancer patients and should be considered as a reasonable option for these patients.

Keywords: QOL; Radical cystectomy; Bladder sparing therapy

\section{Introduction}

Quality Of Life (QOL) has been recognized as an important outcome measure following the treatment of urological malignancies [1]. This concept has been observed in other genitourinary malignancies $[2,3]$. In bladder cancer patients, radical cystectomy is known to be one of the most traumatic cancer operations in terms of psychological stress and alteration in life-style [4]. Several studies have attempted to address QOL following radical cystectomy [5-9]. Transurethral resection, chemotherapy, and radiation with salvage cystectomy may be used in selected patients as alternatives to immediate radical cystectomy for the treatment of invasive bladder cancer. In this conservative approach, overall survival rates appear to be comparable to modern radical cystectomy series, with the majority of survivors retaining their bladder, with normal urinary function. Comparisons between surgical series and conservative approach are hindered by the difference in pathologic staging (used in surgical series) and clinical staging (used in bladder preservation series). Therefore, no prospective randomized trial to compare both modalities has been performed [10]. Retrospective studies reported that preservation of the diseased bladder resulted in favorable outcome regarding QOL [11-13]. Lukka [14] stated that urodynamic and QOL studies have shown that patients with bladder preserving therapy have well-functioning bladders and have mild bowel symptoms following modern radiotherapy techniques with accurate 3-D planning, conformal radiation therapy. The favorable QOL outcome in bladder cancer patients after tri-modality bladder sparing therapy was reported by Zietman et al. [13] and Michaelson et al. [15].

On the other hand, erectile dysfunction was reported in $87-92 \%$ of patients after radical cystectomy [12,16]. Heningssohn et al. [17] found that distress in postcystectomy patients was due to a compromised sexual function, urinary problems and bowel dysfunction. In a large group of patients, men reported an overall potency rate of $38 \%$ [18].
Many studies comparing patients with orthotopic diversion versus ileal conduit yielded a heterogeneous picture in terms of general health status, physical functions, bowl symptoms, the subjective quality of life assessment [19-24].

The aim of this study was to evaluate the impact of radical cystectomy and orthotopic bladder reconstruction versus bladder preservation protocol on the QOL of patients with bladder cancer.

\section{Patients and Methods}

This is a prospective study that included patients with muscleinvasive bladder cancer (clinical stage T2-T3 N0-1 M0). Patients were non-randomly assigned into 2 groups. Group 1 included patients who underwent bladder preservation protocols with tri-modality therapy (Complete TUR, and concurrent chemo-radiation). Radiation therapy was initiated 4 weeks after TUR using $15 \mathrm{MV}$ photons and a 3-field technique with daily fractions of $2.0 \mathrm{~Gy}$ on 5 consecutive days. The total dose was $66 \mathrm{~Gy}$ to the tumor volume, $56 \mathrm{~Gy}$ to whole bladder and $46 \mathrm{~Gy}$ to the pelvis. Chemotherapy, Gemcitabine was given at $30 \mathrm{mg} / \mathrm{m}^{2}$ by 30 minute intravenous infusion before radiation therapy sessions twice weekly. Group 2 included those underwent radical cystectomy and orthotopic neo-bladder carried out applying the technique published by

*Corresponding author: Mohamed Ibrahim El-Sayed, Radiation Oncology Department, South Egypt Cancer Institute, Al-Mthaq St., Assiut 71111, Egypt, Tel: +20-122953887; Fax: +20-882348609; E-mail: mohebel@yahoo.co.uk

Received March 21, 2013; Accepted May 02, 2013; Published May 04, 2013

Citation: El-Sayed MI, El-Azab AS, El-Gammal MA (2013) Quality of Life in Bladder Cancer Patients Treated with Radical Cystectomy and Orthotopic Bladder Reconstruction versus Bladder Preservation Protocol. J Cancer Sci Ther 5: 190 193. doi:10.4172/1948-5956.1000205

Copyright: (c) El-Sayed MI, et al. This is an open-access article distributed unde the terms of the Creative Commons Attribution License, which permits unrestricted use, distribution, and reproduction in any medium, provided the original author and source are credited. 
Hautmann et al. [25]. All patients in this group recieved postoperative radiation therapy with radiation dose of 50 Gy/25 fractions over 5 weeks. This study was carried out during the period from September, 2011 to February 2013. The study protocol was approved by the local institutional review board at South Egypt Cancer Institute, Assiut University. Informed consent was obtained from all patients. Three months after assigning patients to the appropriate treatment modality, QOL was assessed using the NCCN-FACT questionnaire. This questionnaire is general non specific tool that assess QOL in bladder cancer patients. The questionnaire was administered in the oncology outpatient clinic during the 3 months follow up visits.

\section{Interviewing bladder cancer patients for NCCN-FACT FBISI18 questionnaire}

Bladder cancer patients were stratified into two groups; Group I included patients with bladder preservation and Group II included those with orthotopic bladder reconstruction. Patients in both groups were subjected to interview questionnaire consisting of 18 items and were asked questions inquiring about physical and emotional disease related symptoms, treatment side effects and function and well being. Participants were asked the proposed questionnaire [NCCN-FACT FBISI18 "See appendix"] to assess quality of life in both groups. The timing of administering the questionnaire has a great influence on the outcome of the questionnaire. Patients' point of view may change over a short period of time. The questionnaire was administered to all study subjects at specific time, 3 months after completion of therapy to avoid bias.

The response is a 5-Likert category ranging from "not at all (0)", "to a little bit (1)", "to somewhat (2)", "to quite a bit (3)", "to very much (4)".

The NCCN-FACT FBISI18 item means \pm SD were assessed. Patients used the full range of responses (0 to 4 ). The NCCN-FACT FBISI18 subscale total score was calculated by summing all items after reverse coding 12 of the 18 items. The possible range for this subscale is 0 to 72 .

\section{Statistical data analysis}

SPSS version 18 software was used for statistical analysis. Cronbach's a was used to determine internal consistency of the 18 items of NCCNFACT FBISI18 questionnaire. Significance was determined by using the two-sided t test, Pearson's chi-square test, or Fisher's exact test.
Multivariate analysis was done using Cox- regression method. An error probability of $\mathrm{p} \leq 0.05$ was defined as the significance limit.

\section{Results}

Between September 2011 and February 2013, 73 patients were enrolled. Baseline patients' characteristics are summarized in Table 1. The median age at the time of study enrollment was 55 years (range: $36-75)$. There were male predominance in the whole study $58(79.5 \%)$, and in both groups ( $81 \%$ and $78 \%$ in groups I and II respectively), with a male to female ratio of 3.9:1. The majority of patients had ECOG performance status score of 1 (90\%), and had T2 (66\%), N0 (68.5\%), and grade $2(57.5 \%)$ disease. There were no statistically significant differences between the two groups regarding patients' characteristics $(\mathrm{p}<0.05)$ (Table 1$)$. In postcystectomy patients, early postoperative complications included only 3 patients with wound complications (dehiscent wound) that required secondary sutures.

Internal consistency as assessed using Cronbach's a was 0.89 at Group I and 0.84 at Group II. The individual and overall scores of the questionnaire were significantly higher among subjects treated with the bladder preservation protocol when compared to those treated with radical cystectomy and orthotopic diversion. Univariate analysis showed that there were statistically significant difference $(p<0.05)$ in favor of bladder preservation patients (Group I), compared to patients with orthotopic reconstruction (Group II), regarding all physical and emotional disease related symptoms, and treatment side effects. Regarding function and well being subscale, the differences between the two groups were not significant $(p>0.05)$ (Table 2). Multivariate analysis showed that only $\mathrm{T}$ stage significantly affected pain, weight loss, and dizziness (physical disease related symptoms), sadness (an emotional disease related symptom), and nausea, lack of energy, and bothering of treatment side effects (treatment side effects subscale) in favor of group I (bladder preservation) (Table 3).

\section{Discussion}

Multimodality bladder-preserving treatment in localized disease represents a safe and effective alternative to immediate RC [26] However, surgery and bladder-preserving therapy should be seen as complementary rather than competing strategies and organ preservation is not for all patients, but for unfit patients [27]. Patient undergoing bladder-preserving therapy should be selected, well

\begin{tabular}{|c|c|c|c|c|}
\hline & $\begin{array}{l}\text { Total } \\
N=73\end{array}$ & $\begin{array}{l}\text { Bladder preservation protocol (Group I) } \\
\qquad \mathrm{N}=36\end{array}$ & $\begin{array}{l}\text { Orthotopic bladder reconstruction } \\
\qquad \begin{array}{l}\text { (Group II) } \\
N=37\end{array}\end{array}$ & \multirow[t]{2}{*}{$P$ value } \\
\hline & N0 (\%) & N0 (\%) & N0 (\%) & \\
\hline $\begin{array}{l}\text { Age } \\
\text { Median } \\
\text { range }\end{array}$ & $\begin{array}{c}55 \text { years } \\
36-75 \text { years }\end{array}$ & $\begin{array}{c}55 \text { years } \\
36-75 \text { years }\end{array}$ & $\begin{array}{c}56 \text { years } \\
37-72 \text { years }\end{array}$ & \\
\hline $\begin{array}{l}\text { Gender } \\
\text { Female } \\
\text { Male }\end{array}$ & $\begin{array}{l}15(20.5) \\
58(79.5)\end{array}$ & $\begin{array}{c}7(19.4) \\
29(80.6)\end{array}$ & $\begin{array}{c}8(21.6) \\
29(78.4)\end{array}$ & $>0.05$ \\
\hline $\begin{array}{l}\text { Perf. status (ECOG) } \\
1 \\
2\end{array}$ & $\begin{array}{c}66(90.4) \\
7(9.6)\end{array}$ & $\begin{array}{c}33(91.7) \\
3(8.3)\end{array}$ & $\begin{array}{c}33(89.2) \\
4(10.8)\end{array}$ & $>0.05$ \\
\hline $\begin{array}{l}\text { T stage } \\
\text { T2 } \\
\text { T3 }\end{array}$ & $\begin{array}{l}48(65.8) \\
25(34.2)\end{array}$ & $\begin{array}{l}26(72.2) \\
10(27.8)\end{array}$ & $\begin{array}{l}22(59.5) \\
15(40.5)\end{array}$ & $>0.05$ \\
\hline $\begin{array}{l}\text { N stage } \\
\text { N0 } \\
\text { N1 }\end{array}$ & $\begin{array}{l}50(68.5) \\
23(31.5)\end{array}$ & $\begin{array}{l}26(72.2) \\
10(27.8)\end{array}$ & $\begin{array}{l}24(64.9) \\
13(35.1)\end{array}$ & $>0.05$ \\
\hline $\begin{array}{l}\text { Histologic grade } \\
\text { G1 } \\
\text { G2 } \\
\text { G3 }\end{array}$ & $\begin{array}{c}3(4.1) \\
42(57.5) \\
28(38.4)\end{array}$ & $\begin{array}{c}1(2.8) \\
18(50) \\
17(47.2)\end{array}$ & $\begin{array}{c}2(5.4) \\
24(64.9) \\
11(29.7)\end{array}$ & $>0.05$ \\
\hline Total & 73 (100) & $36(49.3)$ & $37(50.7)$ & \\
\hline
\end{tabular}

Table 1: Bladder cancer patient's characteristics 
Citation: El-Sayed MI, El-Azab AS, El-Gammal MA (2013) Quality of Life in Bladder Cancer Patients Treated with Radical Cystectomy and Orthotopic Bladder Reconstruction versus Bladder Preservation Protocol. J Cancer Sci Ther 5: 190-193. doi:10.4172/1948-5956.1000205

\begin{tabular}{|c|c|c|c|c|}
\hline & \multirow{2}{*}{ Questionnaire Item } & \multicolumn{2}{|c|}{ Mean \pm SD values } & \multirow{2}{*}{$P$ value } \\
\hline & & $\begin{array}{l}\text { Bladder preservation } \\
\text { (Group I) }\end{array}$ & $\begin{array}{c}\text { Orthotopic reconstruction } \\
\text { (Group II) }\end{array}$ & \\
\hline \multirow{9}{*}{$\begin{array}{l}\text { Physical disease related symptoms } \\
\text { subscale }\end{array}$} & Pain & $3.1 \pm 0.9$ & $2 \pm 1.1$ & 0.0002 \\
\hline & Weight loss & $3.3 \pm 0.7$ & $2.4 \pm 1.6$ & 0.0001 \\
\hline & Trouble in urine control & $2.9 \pm 0.8$ & $1.8 \pm 1.2$ & $<0.0001$ \\
\hline & General weakness & $2.9 \pm 0.8$ & $2 \pm 1.1$ & $<0.0001$ \\
\hline & Dizziness & $3.3 \pm 0.7$ & $2.2 \pm 1$ & $<0.0001$ \\
\hline & Trouble in meeting family needs & $3 \pm 0.9$ & $1.9 \pm 1.2$ & $<0.0001$ \\
\hline & Appetite & $3.3 \pm 0.7$ & $1.1 \pm 1.1$ & 0.0039 \\
\hline & (For men only) Erection & $2.6 \pm 0.9$ & $1.1 \pm 0.7$ & 0.0008 \\
\hline & Good sleeping & $2.5 \pm 0.9$ & $1.3 \pm 1.1$ & $<0.0001$ \\
\hline \multirow{2}{*}{$\begin{array}{l}\text { Emotional disease related symptoms } \\
\text { subscale }\end{array}$} & Worry about the illness & $2.4 \pm 1.2$ & $1.6 \pm 1.4$ & 0.0026 \\
\hline & Sadness & $2.9 \pm 0.8$ & $1.6 \pm 1$ & $<0.0001$ \\
\hline \multirow{5}{*}{ Treatment side effects subscale } & Nausea & $3.3 \pm 0.7$ & $2.2 \pm 1.8$ & $<0.0001$ \\
\hline & Lack of energy & $2.9 \pm 1$ & $1.8 \pm 0.9$ & $<0.0001$ \\
\hline & Feeling ill & $2.8 \pm 1.1$ & $2.4 \pm 1.4$ & $<0.0001$ \\
\hline & Bowels control & $3.4 \pm 1.5$ & $1.7 \pm 0.8$ & $<0.0001$ \\
\hline & Bothering from treatment side effects & $3.1 \pm 0.9$ & $1.5 \pm 0.9$ & $<0.0001$ \\
\hline \multirow{2}{*}{ Function and well being subscale } & Enjoying life & $1.6 \pm 0.9$ & $1.5 \pm 1.1$ & 0.352 \\
\hline & Satisfaction with quality of life & $1.7 \pm 1.1$ & $1.5 \pm 1.2$ & 0.438 \\
\hline Total & & $51 \pm 16.5$ & $26.8 \pm 20.6$ & \\
\hline
\end{tabular}

Table 2: Univariate analysis in bladder cancer patients in both groups

\begin{tabular}{|c|c|c|c|c|}
\hline \multicolumn{2}{|l|}{ Questionnaire Item } & \multirow{2}{*}{$\begin{array}{c}\text { P value } \\
0.017\end{array}$} & \multirow{2}{*}{$\begin{array}{c}\text { Hazard Ratio } \\
12.533\end{array}$} & \multirow{2}{*}{$\begin{array}{c}\mathbf{9 5 \%} \mathbf{C l} \\
1.56-100.65\end{array}$} \\
\hline \multirow{3}{*}{$\begin{array}{l}\text { Physical disease related symptoms } \\
\text { subscale }\end{array}$} & Pain & & & \\
\hline & Weight loss & 0.029 & 4.68 & $1.17-18.74$ \\
\hline & Dizziness & 0.044 & 3.56 & $1.03-12.25$ \\
\hline $\begin{array}{l}\text { Emotional disease related symptoms } \\
\text { subscale }\end{array}$ & Sadness & 0.022 & 11.48 & $1.43-92.08$ \\
\hline \multirow{3}{*}{ Treatment side effects subscale } & Nausea & 0.045 & 3.46 & $1.03-11.70$ \\
\hline & Lack of energy & 0.027 & 10.54 & $1.31-84.56$ \\
\hline & Bothering from side effects of treatment & 0.028 & 4.56 & $1.18-17.63$ \\
\hline
\end{tabular}

Table 3: Multivariate analysis of factors affecting QOL in bladder cancer patients

informed, and compliant for whom cystectomy is not considered for medical or personal reasons [28].

The effects of treatment modality on the psychological, functional, and social life of cancer patients are well established end points of cancer therapy and not only response and survival rates [29]. At the present time, continent urinary diversion - as orthotopic neobladder - after total cystectomy is commonly done. Orthotopic bladder reconstructions [30] as well as complete TUR and chemo-radiation for bladder preservation [14] have positive impact on patients' physical, emotional, social aspects of QOL. In contrast to the vast majority of available studies that are retrospective and cross-sectional, the present study was none randomized and prospectively addressed the concern of impact of orthotopic neobladder (after radical cystectomy) versus bladder preservation (after tri-modality therapy) on patients' QOL. Although randomized controlled trials are the most reliable form of scientific evidence because they reduce spurious causality and selection bias, they are not always feasible or ethical to do, in which case it is likely that non-randomized experiments will be used. The recent central hypothesis about the use of non randomized studies is that they yield results that approximate randomized trials [31]. To avoid selection bias, pretreatment factors that might be confounding and affect outcome were adjusted. In the present study, there were no significant difference among both groups as regard age, sex, and tumor stage.
A validated quality of life questionnaire (NCCN-FACT-FBISI-18) was used to evaluate the impact of treatment modality on our patients with muscle invasive bladder cancer. Our results show acceptable NCCN-FACT-FBISI-18 reliability and validity. As assessed by Cronbach's $\alpha$, internal consistency exceeded 0.8 for both bladder preservation as well as orthotopic neobladder subscales. Therefore, the authors of the present study considered that the 18 items of the used questionnaire collectively reflected bladder cancer specific QOL.

Univariate analysis in the current study, showed that there were statistically significant differences $(\mathrm{p}<0.05)$ between the two treatment modality groups in favor of bladder preserving therapy group compared to orthotopic neobladder group, regarding all physical and emotional disease related symptoms (indicating good bladder function and for men satisfactory potency), and treatment side effects (especially mild bowel symptoms). Quality of life was assessed among our study subjects 3 months after completion of therapy. The effect of early postoperative complications that might affect patient satisfaction with treatment should have gone.

Multivariate analysis revealed that only T stage significantly affected physical and emotional disease related symptoms, and treatment side effects subscales in favor of bladder preservation group.

Superior QOL in bladder preserving therapy group could not be attributed to patients' age, gender, and performance status as well as to tumor factors as TNM stage and histologic grade as there were 
no significant difference between the two groups regarding patients' characteristics. Favorable QOL in group I may be explained by criteria associated with good response to tri-modality treatment as unifocal and small $(<5 \mathrm{~cm}$ in maximum diameter) primary tumor with no ureteric obstruction, and good bladder capacity [32]. These factors may not present in cystectomy group. Furthermore, potency and sexual activity are strongly correlated with autonomic nerve preservation [33] that could not most commonly be obtained during cystectomy and urinary diversion, but achieved with bladder preservation protocols. Our findings are matched with results of many reported studies that supported a favorable QOL outcome in bladder preservation group [1216] and relatively unfavorable outcome in orthotopic reconstruction group [17-24].

\section{Conclusions}

Bladder cancer patients who underwent tri-modality bladder sparing therapy have well-functioning bladders, mild bowel symptoms, and satisfactory sexual functioning. Therefore, it should be considered as a reasonable option to these patients. Direct comparison of bladder preservation and surgical approaches should be addressed in a randomized study to have a definite conclusion that would guide patient care.

\section{Acknowledgements}

The authors received no financial or other support for the research reported in this manuscript.

\section{Authors' Contributions}

MIE participated in radiation therapy given to patients in bladder preservation approach, designed the study, interviewing patients for NCCN-FACT FBISI18 questionnaire, collected the data on spread sheet, statistical analysis, manuscript drafting and writing the final manuscript.

ASE participated in surgical approach, shared in study design, interviewing patients for NCCN-FACT FBISI18 questionnaire, shared in collecting data on a spread sheet and reviewed the manuscript.

MAE participated in surgical approach, interviewing patients for NCCN-FACT FBISI18 questionnaire, shared in collecting data on a spread sheet and reviewed the manuscript. All authors read and approved the final manuscript.

\section{References}

1. Cookson MS, Dutta SC, Chang SS, Clark T, Smith JA Jr, et al. (2003) Health related quality of life in patients treated with radical cystectomy and urinary diversion for urothelial carcinoma of the bladder: development and validation of a new disease specific questionnaire. J Urol 170: 1926-1930.

2. Litwin MS, Hays RD, Fink A, Ganz PA, Leake B, et al. (1998) The UCLA Prostate Cancer Index: development, reliability, and validity of a health-related quality of life measure. Med Care 36: 1002-1012.

3. Herr HW (1997) Quality of life in prostate cancer patients. CA Cancer J Clin 47: 207-217.

4. Månsson A, Månsson W (1999) When the bladder is gone: quality of life following different types of urinary diversion. World J Urol 17: 211-218.

5. Dutta SC, Chang SC, Coffey CS, Smith JA Jr, Jack G, et al. (2002) Health related quality of life assessment after radical cystectomy: comparison of ileal conduit with continent orthotopic neobladder. J Urol 168: 164-167.

6. Hardt J, Filipas D, Hohenfellner R, Egle UT (2000) Quality of life in patients with bladder carcinoma after cystectomy: first results of a prospective study. Qual Life Res 9: 1-12

7. Hart S, Skinner EC, Meyerowitz BE, Boyd S, Lieskovsky G, et al. (1999) Quality of life after radical cystectomy for bladder cancer in patients with an ileal conduit, cutaneous or urethral kock pouch. J Urol 162: 77-81.

8. Kitamura H, Miyao N, Yanase M, Masumori N, Matsukawa M, et al. (1999) Quality of life in patients having an ileal conduit, continent reservoir or orthotopic neobladder after cystectomy for bladder carcinoma. Int J Urol 6: 393-399.

9. Skinner EC (2001) Quality of life with reconstruction. Semin Urol Oncol 19: 56-58.

10. Torres-Roca JF (2004) Bladder preservation protocols in the treatment of muscle-invasive bladder cancer. Cancer Control 11: 358-363.

11. Lynch WJ, Jenkins BJ, Fowler CG, Hope-Stone HF, Blandy JP (1992) The quality of life after radical radiotherapy for bladder cancer. Br J Urol 70: 519-521.
12. Caffo O, Fellin G, Graffer U, Luciani L (1996) Assessment of quality of life after cystectomy or conservative therapy for patients with infiltrating bladder carcinoma. A survey by a self-administered questionnaire. Cancer 78: 10891097.

13. Zietman AL, Sacco D, Skowronski U, Gomery P, Kaufman DS, et al. (2003) Organ conservation in invasive bladder cancer by transurethral resection, chemotherapy and radiation: results of a urodynamic and quality of life study on long-term survivors. J Urol 170: 1772-1776.

14. Lukka H (2009) In favour of bladder preservation using combined modality treatment. Can Urol Assoc J 3: 412-415.

15. Michaelson D, Zietman A (2003) Invasive Bladder Cancer: The role of bladderpreserving therapy. Am J Clin Oncol 1092- 9118/03/457-465.

16. Henningsohn L, Wijkström H, Dickman PW, Bergmark K, Steineck G (2002) Distressful symptoms after radical radiotherapy for urinary bladder cancer. Radiother Oncol 62: 215-225

17. Henningsohn L, Steven K, Kallestrup EB, Steineck G (2002) Distressfu symptoms and well-being after radical cystectomy and orthotopic bladder substitution compared with a matched control population. J Urol 168: 168-174.

18. Studer UE, Burkhard FC, Schumacher M, Kessler TM, Thoeny $\mathrm{H}$, et al. (2006) Twenty years experience with an ileal orthotopic low pressure bladder substitute--lessons to be learned. J Urol 176: 161-166.

19. Shih C, Porter MP (2011) Health-related quality of life after cystectomy and urinary diversion for bladder cancer. Adv Urol 2011: 715892.

20. Erber B, Schrader M, Miller K, Schostak M, Baumunk D, et al. (2012) Morbidity and quality of life in bladder cancer patients following cystectomy and urinary diversion: A single-institution comparison of ileal conduit versus orthotopic neobladder. ISRN Urol 2012: 342796.

21. Sogni F, Brausi M, Frea B, Martinengo C, Faggiano F, et al. (2008) Morbidity and quality of life in elderly patients receiving ileal conduit or orthotopic neobladder after radical cystectomy for invasive bladder cancer. Urology 71 919-923.

22. Saika T, Arata R, Tsushima T, Nasu Y, Suyama B, et al. (2007) Health-related quality of life after radical cystectomy for bladder cancer in elderly patients with an ileal conduit, uretero-cutaneostomy, or orthotopic urinary reservoir: a comparative questionnaire survey. Acta Medica Okayama 61: 199-203.

23. Dutta SC, Chang SC, Coffey CS, Smith JA Jr, Jack G, et al. (2002) Health related quality of life assessment after radical cystectomy: comparison of ileal conduit with continent orthotopic neobladder. J Urol 168: 164-167.

24. Autorino R, Quarto G, Di Lorenzo G, De Sio M, Perdonà S, et al. (2009) Health related quality of life after radical cystectomy: comparison of ileal conduit to continent orthotopic neobladder. Eur J Surg Oncol 35: 858-864.

25. Hautmann RE (2003) Urinary diversion: ileal conduit to neobladder. J Urol 169 834-842.

26. Gakis G, Efstathiou J, Lerner SP, Cookson MS, Keegan KA, et al. (2013) ICUDEAU International Consultation on Bladder Cancer 2012: radical cystectomy and bladder preservation for muscle-invasive urothelial carcinoma of the bladder. Eur Urol 63: 45-57.

27. Caffo O, Veccia A, Fellin G, Russo L, Mussari S, et al. (2013) Trimodality treatment in the conservative management of infiltrating bladder cancer: $A$ critical review of the literature. Crit Rev Oncol Hematol 86: 176-190.

28. Stenzl A, Cowan NC, De Santis M, Kuczyk MA, Merseburger AS, et al. (2012) [Treatment of muscle-invasive and metastatic bladder cancer: update of the EAU guidelines]. Actas Urol Esp 36: 449-460.

29. Hermerén G (1992) Surgery, cancer and quality of life: ethical aspects. Scand J Urol Nephrol Suppl 142: 15-18.

30. Hara I, Miyake H, Hara S, Gotoh A, Nakamura I, et al. (2002) Health-related quality of life after radical cystectomy for bladder cancer: a comparison of ileal conduit and orthotopic bladder replacement. BJU Int 89: 10-13.

31. Shadish WR (2011) Randomized controlled studies and alternative designs in outcome studies: challenges and opportunities. Res Soc Work Pract 21: 636643.

32. Zeitman A, Shipley W (2007) Clinical Radiation Oncology. In: Gunderson \& Tepper eds Churchill Livingstone Elsevier: 1237-1260.

33. Stenzl A, Sherif H, Kuczyk M (2010) Radical cystectomy with orthotopic neobladder for invasive bladder cancer: a critical analysis of long term oncological, functional and quality of life results. Int Braz J Urol 36: 537-547. 